\title{
Convective Instability in the Ice Edge Area of the Barents Sea
}

\author{
Vladimir Kushnir ${ }^{1}$, Vladimir Pavlov ${ }^{2, *}$, Alexey Morozov $^{1}$ and Olga Pavlova ${ }^{2}$ \\ ${ }^{1}$ Marine Hydrophysical Institute, National Academy of Science of Ukraine, Sevastopol 99011, Ukraine and ${ }^{2}$ Norwegian \\ Polar Institute, Troms\$ N-9296, Norway
}

\begin{abstract}
The ice edge of the Barents Sea east of Svalbard is an area where the warm, salty water of the North Atlantic (AtW) interacts with cold, less dense, saline Arctic water (ArW) and the water produced by melting ice (MIW). Many of the CTD profiles (CTD stands for Conductivity-Temperature-Depth) obtained in this region by Norwegian Polar Institute expeditions in 1999 and 2007 contain layers that are quasi-homogeneous in temperature, salinity and density between the depths of 5-7 $\mathrm{m}$ to $100-150 \mathrm{~m}$. It is shown that these features are formed by convective instability due to double-diffusion, which can occur where there are positive vertical gradients of both temperature and salinity, as is observed in this region. The rate of development and the thickness of the gradient layer depend on vertical temperature and salinity drops in the zone of interaction of AtW with ArW and MIW. They correspond well, characterized by a correlation coefficient of 0.96 .
\end{abstract}

Key Words: Barents Sea, convection, ice edge, polar front.

\section{INTRODUCTION}

The Barents Sea is an area where the warm, salty waters of the Northern Atlantic (AtW) interact with less salty, cold Arctic waters (ArW) and locally generated water from melting ice (MIW) [1]. The interaction of water masses with different thermohaline characteristics has a strong influence on horizontal and vertical mixing. This influences the transformation of AtW where it enters the Arctic basin through the Barents Sea, and also the transport of nutrients in the surface layer of the sea where photosynthesis takes place, and thus on the initial production characteristics.

The main interaction between AtW and ArW occurs in the ice edge areas, approximately corresponding to the position of the Polar Front (PF). The structure of the ice edge areas represents a congestion of ice fields of the various sizes, clearly visible in a satellite picture of the western part of the Barents Sea from the spring of 1999 (Fig. 1). This structure has allowed Norwegian Polar Institute expeditions to carry out oceanographic surveys in spring 1999 and 2000 at distance up to $100-120$ miles north of the border of the open sea. Fig. (2) shows the locations of the CTD-stations carried out by these surveys and the topography of the area (CTD stands for Conductivity-Temperature-Depth).

The main feature of the vertical thermohaline structures in the ice edge area south-east of Svalbard is the zone of interaction of the AtW (Temperature $(\mathrm{T})=1.5$ to $2^{\circ} \mathrm{C}$, Salinity $(\mathrm{S})=35 \mathrm{psu}$, Density $(\mathrm{D})=1028 \mathrm{~kg} \mathrm{~m}^{-3}$ ) with ArW and MIW ( $\mathrm{T}=-1.5$ to $-2^{\circ} \mathrm{C}, \mathrm{S}=34.4$ to $34.7 \mathrm{psu}, \mathrm{D}=1027.7$ to $1027.9 \mathrm{~kg} \mathrm{~m}^{-3}$ ). ArW and MIW are less dense than AtW and consequently these waters form a surface layer above the

*Address correspondence to this author at the Norwegian Polar Institute, Polar Environmental Centre, Troms $\&$ N-9296, Norway; Tel: +47 77750516; Fax:+47 77750501; E-mail: pavlov@npolar.no layer of warm, salty water. Positive vertical gradients of both temperature and salinity and a stable density stratification create conditions for the development of double diffusive convective processes such as level-by-level convection. Double diffusion occurs because the vertical diffusion of heat takes place faster than that of salt. The warming of overlying layers results in the development of a convective instability, which leads to mixing and the formation of uniform layers of temperature, salinity and density.

The mechanisms of this type of convective process are discussed in [2-22]. The formation of convective layers in lakes, seas and oceans, where temperature and salinity increase with depth, have been demonstrated in [23-36]. Convective uniform layers with thicknesses of 20 - $50 \mathrm{~m}$ were found in the Arctic Ocean at $84^{\circ} \mathrm{N}, 126^{\circ} \mathrm{W}$ in November 1969 in an area where Arctic waters and warmer, salty and denser Atlantic waters come into contact [37]. This layered structure was found at depths from $200 \mathrm{~m}$ up to $500 \mathrm{~m}$. The temperature here increases from $-1^{\circ} \mathrm{C}$ at $200 \mathrm{~m}$ to $0.5^{\circ} \mathrm{C}$ at $500 \mathrm{~m}$, and salinity increases from 34.3 to $34.9 \mathrm{psu}$ over the same depth interval.

Thermohaline structures with uniform layers with thicknesses from $5-7 \mathrm{~m}$ up to $70-80 \mathrm{~m}$ were found on many CTD-stations in the ice edge zone near Svalbard. Examples are shown in Fig. (3). Some features of such structures and their agreement with Turner's model are considered in [31].

Convective vertical movements play an essential role in vertical mixing, the formation of thermohaline structures, and the transport of nutrients in the ocean's photosynthetic layer [39]. The present work analyses the development of convective instability in an area where AtW comes into contact with ArW \& MIW. We calculate the rate of development of uniform layers and the gradient layers at the borders of the convective layers. We attempt to verify our estimations by 


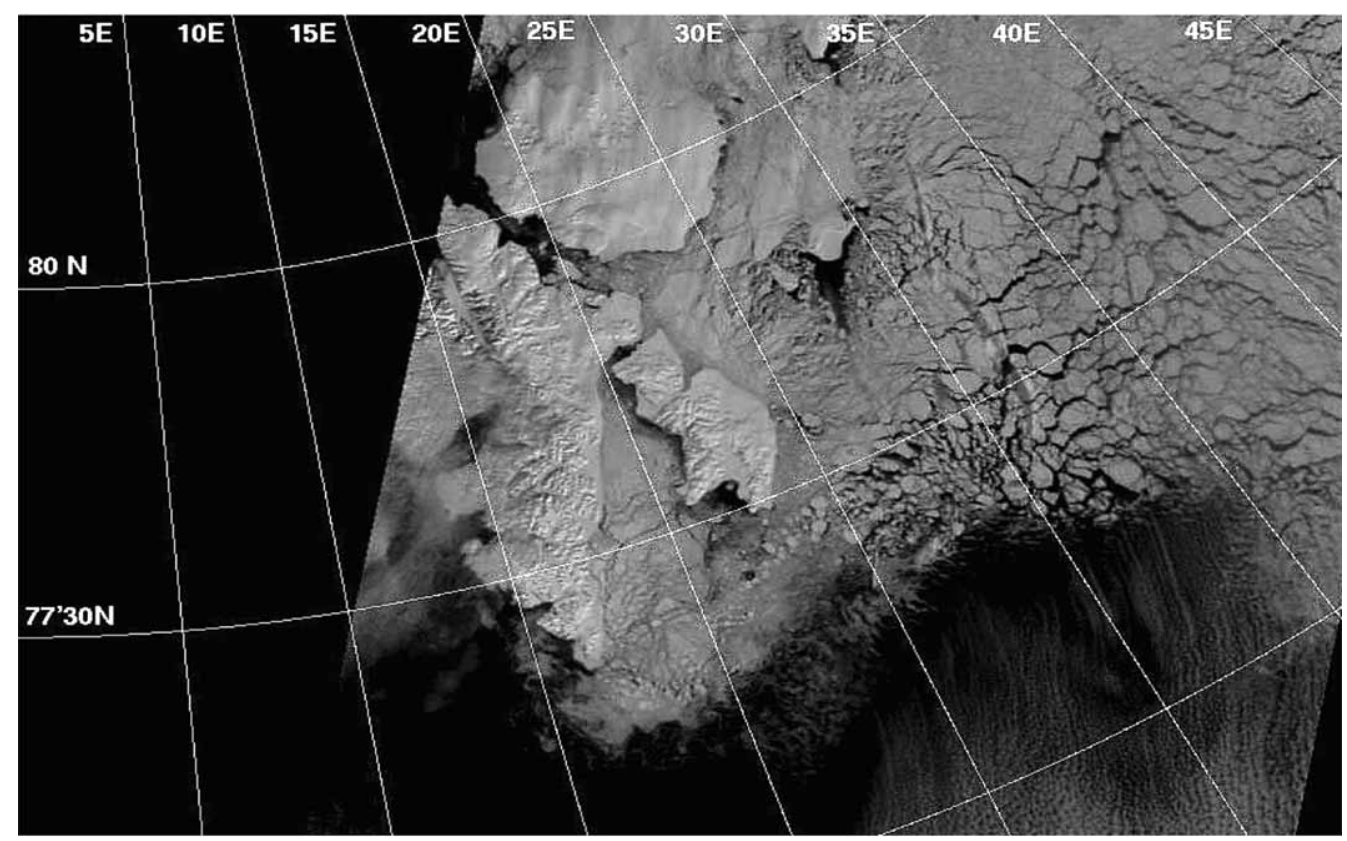

Fig. (1). Satellite image of the ice edge area of the Barents Sea south-east of Svalbard, received in the period of the R/V Lance cruise (04-24 May 1999).

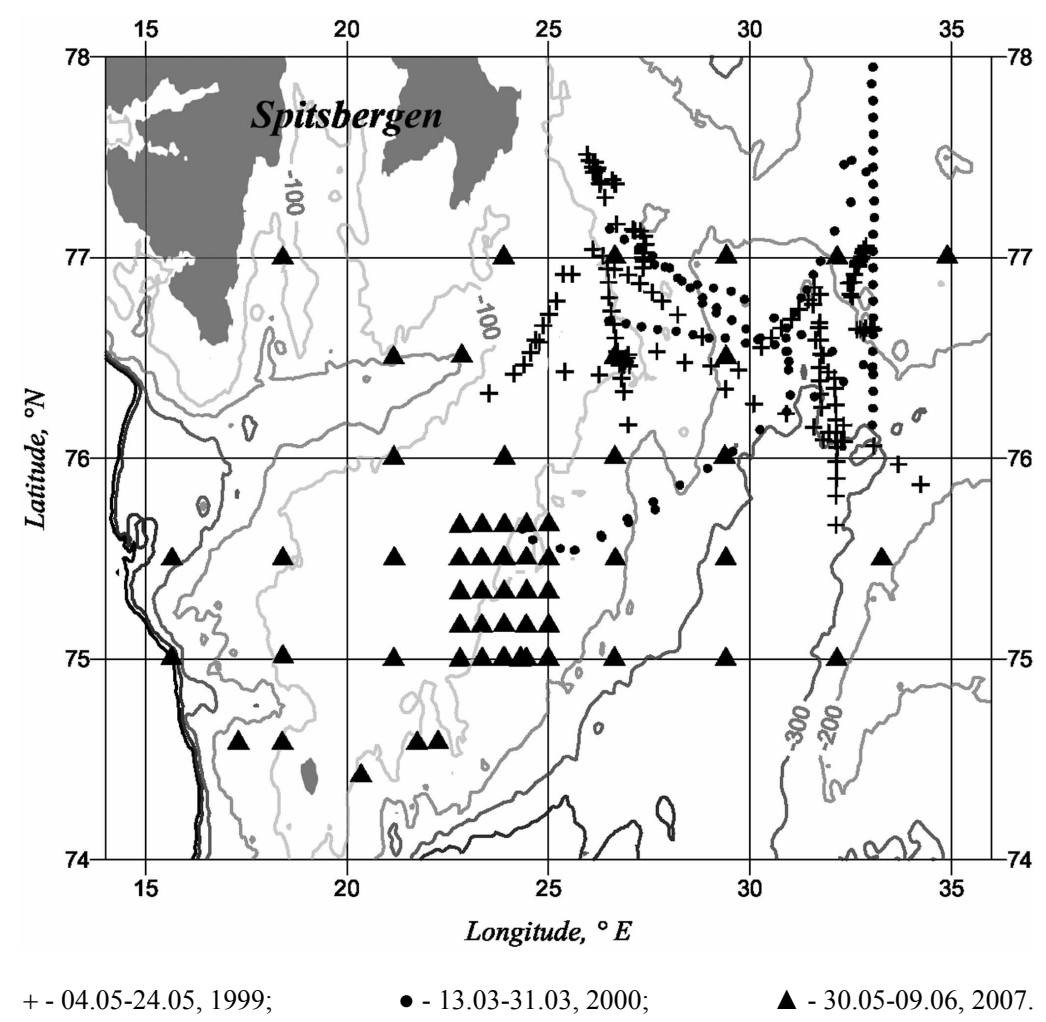

Fig. (2). Locations of the CTD-stations measured by R/V Lance in 1999, 2000 and 2007 in the ice edge zone.

comparison with the observed structures of temperature and salinity.

\section{THE DEVELOPMENT OF A CONVECTIVE IN- STABILITY}

The development of a convective instability starts with the contact of cold, low salinity Arctic waters (ArW) with warmer, salty Northern Atlantic water (AtW). In the limiting case, the contact zone at the initial moment of time is shown in Fig. (4).

The equations of vertical diffusion of temperature, $\mathrm{T}$, and salinity, $\mathrm{S}$, are written as follows:

$$
\frac{\partial \mathrm{T}}{\partial \mathrm{t}}=\mathrm{k}_{\mathrm{t}} \frac{\partial^{2} \mathrm{~T}}{\partial \mathrm{y}^{2}}, \frac{\partial \mathrm{S}}{\partial \mathrm{t}}=\mathrm{k}_{\mathrm{s}} \frac{\partial^{2} \mathrm{~S}}{\partial \mathrm{y}^{2}},
$$



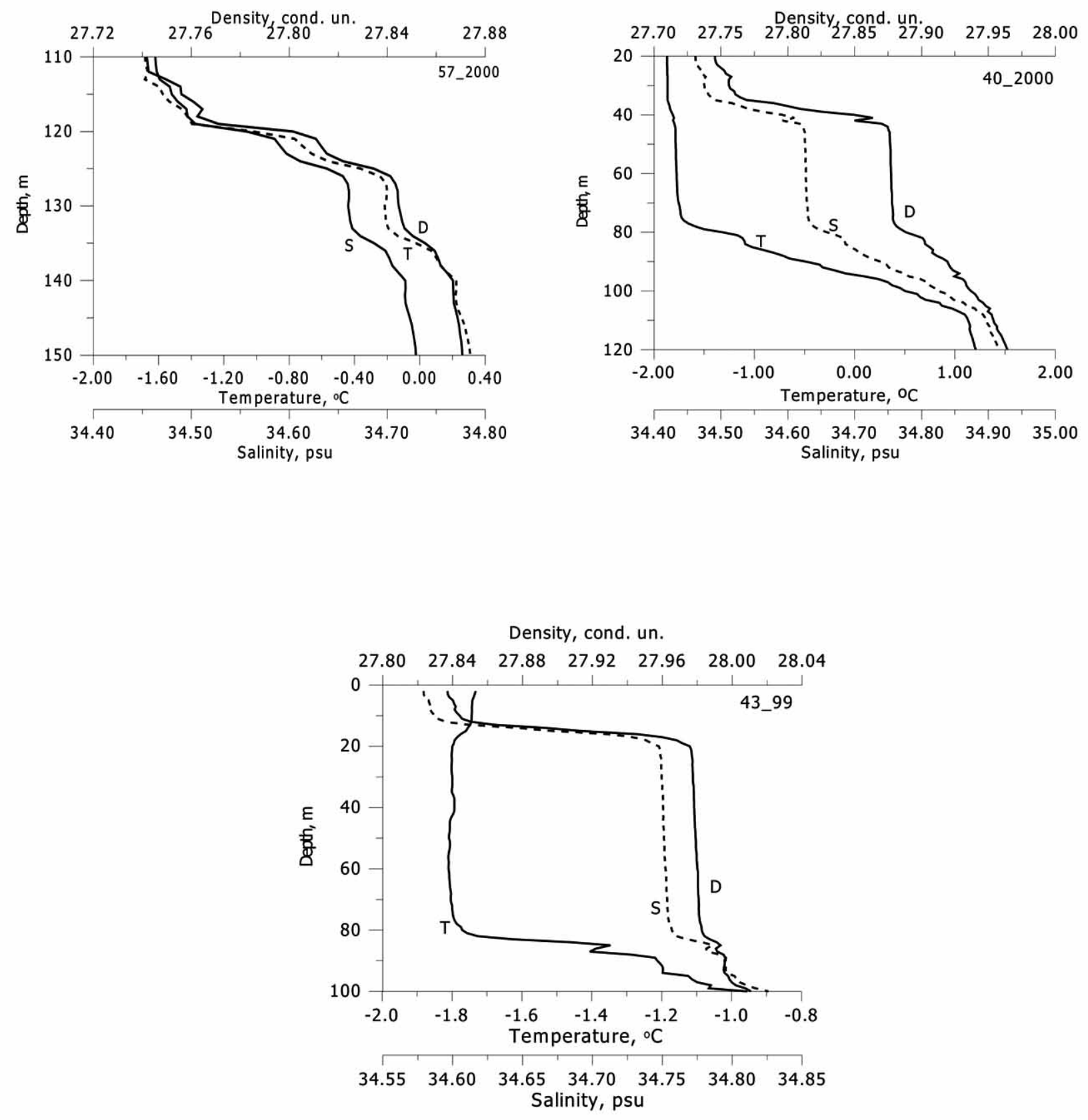

Fig. (3). Examples of the thermohaline structure of the ice edge zone with well-defined layers of convective mixing.

where $t$ is time, and $k_{t}, k_{s}$ are respectively the coefficients of the molecular conductivity of temperature and diffusion of salt.

The initial and boundary conditions are:

$$
\begin{aligned}
& \mathrm{t}=0, \mathrm{y} \geq 0, \quad \mathrm{~T}=\mathrm{T}_{2}, \mathrm{~S}=\mathrm{S}_{2}, \quad \frac{\partial \mathrm{T}(\mathrm{y}=-0)}{\partial \mathrm{y}}=\frac{\partial \mathrm{T}(\mathrm{y}=+0)}{\partial \mathrm{y}}, \\
& \frac{\partial \mathrm{S}(\mathrm{y}=-0)}{\partial \mathrm{y}}=\frac{\partial \mathrm{S}(\mathrm{y}=+0)}{\partial \mathrm{y}}
\end{aligned}
$$




$$
\begin{aligned}
& \mathrm{t}=0, \mathrm{y} \leq 0, \mathrm{~T}=\mathrm{T}_{1}, \mathrm{~S}=\mathrm{S}_{1}, \\
& \mathrm{~T}(\mathrm{y}=-0)=\mathrm{T}(\mathrm{y}=+0)=\mathrm{T}_{\mathrm{m}}=0.5\left(\mathrm{~T}_{1}+\mathrm{T}_{2}\right), \\
& \mathrm{S}(\mathrm{y}=-0)=\mathrm{S}(\mathrm{y}=+0)=\mathrm{S}_{\mathrm{m}}=0.5\left(\mathrm{~S}_{1}+\mathrm{S}_{2}\right)
\end{aligned}
$$

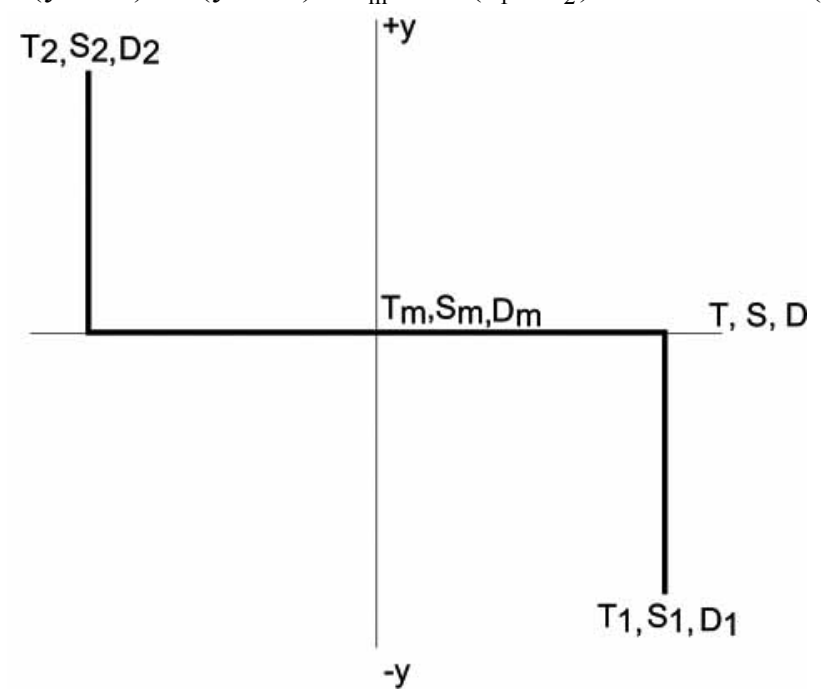

Fig. (4). The contact of $\operatorname{ArW}\left(T_{2}, S_{2}, D_{2}\right)$ with $\operatorname{AtW}\left(T_{1}, S_{1}, D_{1}\right)$ at the initial moment of the development of a convective instability.

The solution of a problem of this type is well-known and has the form

$$
\begin{aligned}
& \mathrm{T}(\mathrm{t}, \mathrm{y} \geq 0)=\mathrm{T}_{\mathrm{m}}+\left(\mathrm{T}_{2}-\mathrm{T}_{\mathrm{m}}\right) \Phi\left(\frac{\mathrm{y}}{2 \sqrt{\mathrm{tk}_{\mathrm{t}}}}\right), \\
& \mathrm{T}(\mathrm{t}, \mathrm{y} \leq 0)=\mathrm{T}_{\mathrm{m}}+\left(\mathrm{T}_{\mathrm{m}}-\mathrm{T}_{1}\right) \Phi\left(\frac{\mathrm{y}}{2 \sqrt{\mathrm{tk}_{\mathrm{t}}}}\right) \\
& \mathrm{S}(\mathrm{t}, \mathrm{y} \geq 0)=\mathrm{S}_{\mathrm{m}}+\left(\mathrm{S}_{2}-\mathrm{S}_{\mathrm{m}}\right) \Phi\left(\frac{\mathrm{y}}{2 \sqrt{\mathrm{tk}_{\mathrm{s}}}}\right), \\
& \mathrm{S}(\mathrm{t}, \mathrm{y} \leq 0)=\mathrm{S}_{\mathrm{m}}+\left(\mathrm{S}_{\mathrm{m}}-\mathrm{S}_{1}\right) \Phi\left(\frac{\mathrm{y}}{2 \sqrt{\mathrm{tk}_{\mathrm{s}}}}\right),
\end{aligned}
$$

where $\Phi(\mathrm{z})=\frac{2}{\sqrt{\pi}} \int_{0}^{\mathrm{z}} \exp \left(-\mathrm{t}^{2}\right) \mathrm{dt}$ is the integral of errors.

The zone of contact between ArW and AtW is usually characterized by a change in temperature from -2 to $+2{ }^{\circ} \mathrm{C}$ and a change in salinity from 34.5 up to $35 \mathrm{psu}$. In this case,

$$
\begin{aligned}
& \Delta \mathrm{T}=\mathrm{T}_{\mathrm{m}}-\mathrm{T}_{2}=1.5^{\circ} \mathrm{C}, \quad \Delta \mathrm{S}=\mathrm{S}_{\mathrm{m}}-\mathrm{S}_{2}=0.25 \quad \mathrm{psu}, \\
& \mathrm{k}_{\mathrm{t}}=1.33 \cdot 10^{-7} \mathrm{~m}^{2} \mathrm{~s}^{-1}, \mathrm{k}_{\mathrm{s}}=1.33 \cdot 10^{-9} \mathrm{~m}^{2} \mathrm{~s}^{-1} .
\end{aligned}
$$

The real thickness of the gradient layer, as seen in Fig. (3), varies from 3 to $15 \mathrm{~m}$, and on some profiles is as much as 45 to $50 \mathrm{~m}$. If we assume, that these gradient layers are formed by molecular diffusion of temperature and salinity, the corresponding timescales are from 76 to 1920 days for temperature and from 760 to 19200 days for salinity, which is unrealistically long. This suggests that turbulent diffusion of temperature and salinity is most important in the formation of such layers. One possible mechanism is considered below.
The parameterization of the vertical temperature flux $F_{T}$ in a zone of contact AtW and ArW can be presented as follows $[7,8,12,13,31,38]$ :

$$
\mathrm{F}_{\mathrm{T}}=\mathrm{K}_{\mathrm{T}} \frac{\Delta \mathrm{T}}{\mathrm{d}_{\mathrm{T}}}
$$

where $\mathrm{K}_{\mathrm{T}}$ is the coefficient of turbulent diffusion of temperature,

$\mathrm{F}_{\mathrm{T}}=8.585 \cdot 10^{-3} \mathrm{k}_{\mathrm{t}}\left(\frac{\alpha \mathrm{g}}{v \mathrm{k}_{\mathrm{t}}}\right)^{0.33} \Delta \mathrm{T}^{1.33} \exp \left\{4.6 \exp \left[-0.54\left(\mathrm{R}_{\mathrm{\rho}}-1\right)\right]\right\} \quad$ is the flux of temperature through this contact zone, $\Delta \mathrm{T}=\mathrm{T}_{\mathrm{m}}-\mathrm{T}_{2}=\mathrm{T}_{1}-\mathrm{T}_{\mathrm{m}}$ is the change of temperature, $\mathrm{d}_{\mathrm{T}}$ is the thickness of the gradient layer at $\mathrm{y} \geq 0, v$ is the molecular viscosity, $\alpha$ is the coefficient of temperature expansion, $\mathrm{g}$ is the gravity acceleration, $\beta$ is the coefficient of salinity compression and $R_{\rho}=\beta \Delta S / \alpha \Delta T$ is the density ratio [38].

The temperature difference $\Delta \mathrm{T}$ and temperature flux $\mathrm{F}_{\mathrm{T}}$ do not vary in a non-stationary case of development of the gradient layer $d_{T}$. The thickness of this gradient layer constantly increases, owing to turbulent diffusion of temperature and, in a general case, this value depends on time as follows: $d_{T} \propto t^{n}$, where $n$ may be any parameter. As the coefficient of turbulent diffusion of temperature $\mathrm{K}_{\mathrm{T}}$ is proportional to $d_{T} \quad\left(K_{T}=\frac{F_{T}}{\Delta T} d_{T}\right.$, see Eq. 5), one can write $\mathrm{K}_{\mathrm{T}}=\mathrm{ct}^{\mathrm{n}}$ and the equation for temperature takes the form:

$\frac{\partial \mathrm{T}}{\partial \mathrm{t}}=\mathrm{ct}^{\mathrm{n}} \frac{\partial^{2} \mathrm{~T}}{\partial \mathrm{y}^{2}}$

with initial and boundary conditions given in Eq. (2) for temperature. The replacement of the variable $\tau=(\mathrm{n}+1)^{-1} \mathrm{t}^{\mathrm{n}+1}$ reduces Eq. (6) to a linear equation with boundary and initial conditions (Eq. 2). The solution of this equation for $\mathrm{y} \geq 0$ has the following form:

$$
\mathrm{T}=\mathrm{T}_{\mathrm{m}}+\Delta \mathrm{T} \Phi\left(\frac{\mathrm{y}}{2 \sqrt{(\mathrm{n}+1)^{-1} \mathrm{ct}^{\mathrm{n}+1}}}\right)=\mathrm{T}_{\mathrm{m}}+\Delta \mathrm{T} \Phi\left(\frac{\mathrm{y}}{2 \sqrt{(\mathrm{n}+1)^{-1} \mathrm{~K}_{\mathrm{T}} \mathrm{t}}}\right)
$$

Since $\mathrm{d}_{\mathrm{T}}=\Delta \mathrm{T} /(\partial \mathrm{T} / \partial \mathrm{y})$ at $\mathrm{y}=0$, so

$$
\begin{aligned}
& \mathrm{d}_{\mathrm{T}}=\frac{1}{\sqrt{\pi(\mathrm{n}+1)^{-1} \mathrm{~K}_{\mathrm{T}} \mathrm{t}}} \text {, and } \\
& \mathrm{K}_{\mathrm{T}}=\frac{\mathrm{F}_{\mathrm{T}} \mathrm{d}_{\mathrm{T}}}{\Delta \mathrm{T}}=\frac{\mathrm{F}_{\mathrm{T}}}{\Delta \mathrm{T}} \sqrt{\pi \mathrm{K}_{\mathrm{T}}(\mathrm{n}+1)^{-1} \mathrm{t}}, \text { or } \\
& \mathrm{K}_{\mathrm{T}}=\pi\left(\frac{\mathrm{F}_{\mathrm{T}}}{\Delta \mathrm{T}}\right)^{2}(\mathrm{n}+1)^{-1} \mathrm{t} .
\end{aligned}
$$

From Eqs. (7) and (8) it follows that for any parameter $n$, the coefficient of turbulent diffusion of temperature is line- 
arly dependent on time and, hence, $\mathrm{n}=1$ and $\mathrm{K}_{\mathrm{T}}=0.5 \pi\left(\frac{\mathrm{F}_{\mathrm{T}}}{\Delta \mathrm{T}}\right)^{2} \mathrm{t}$.

The coefficient of turbulent diffusion of salt, $\mathrm{K}_{\mathrm{S}}$, is determined from the known dependence between $\mathrm{K}_{\mathrm{S}}$ and $\mathrm{K}_{\mathrm{T}}$, and at $R_{\rho} \geq 2[7,10,27]$ from Eq. (8),

$\mathrm{K}_{\mathrm{S}}=\left(0.15 / \mathrm{R}_{\rho}\right) \mathrm{K}_{\mathrm{T}}=\frac{0.075 \pi}{\mathrm{R}_{\rho}}\left(\frac{\mathrm{F}_{\mathrm{T}}}{\Delta \mathrm{T}}\right)^{2} \mathrm{t}$.

For the turbulent mode of diffusion of temperature and salinity in the zone of contact between AtW and ArW, the density varies as

$$
\rho^{\prime}=\frac{\mathrm{D}-\mathrm{D}_{\mathrm{m}}}{\mathrm{D}_{\mathrm{m}}}=\beta \Delta \mathrm{S} \Phi\left(\frac{\mathrm{y}}{2\left(\frac{\mathrm{F}_{\mathrm{T}}}{\Delta \mathrm{T}}\right) \mathrm{t} \sqrt{\frac{0.075 \pi}{\mathrm{R}_{\rho}}}}\right)-\alpha \Delta \mathrm{T} \Phi\left(\frac{\mathrm{y}}{2\left(\frac{\mathrm{F}_{\mathrm{T}}}{\Delta \mathrm{T}}\right) \mathrm{t} \sqrt{0.5 \pi}}\right)
$$

The thickness of the gradient layer, $d_{\rho}$, is determined from the condition $\frac{\partial \rho^{\prime}}{\partial y}=0$, and after transformation,

$$
d_{\rho}=2 \sqrt{t \frac{K_{S} K_{T}}{K_{T}-K_{S}} \ln R_{\rho} \sqrt{\frac{K_{T}}{K_{S}}}}=1.373 t\left(\frac{F_{T}}{\Delta T}\right) \sqrt{\frac{\ln \left(2.58 R_{\rho}^{1.5}\right)}{R_{\rho}-0.15}} .
$$

The heat flux through the zone of contact of AtW and ArW, and the effect on buoyancy connected with it, result in convective mixing. The development of the convective mixing process starts when the Nusselt number $\mathrm{Nu}$ is equivalent to unity,

$\mathrm{Nu}=\frac{\mathrm{F}_{\mathrm{T}} \mathrm{d}_{\mathrm{c}}}{\mathrm{k}_{\mathrm{t}} \Delta \mathrm{T}}=1$,

where $d_{c}$ is the initial thickness of the convective layer,

$$
\mathrm{d}_{\mathrm{c}}=\frac{116.48\left(\mathrm{vk}_{\mathrm{t}}\right)^{0.33}}{(\alpha \mathrm{g} \Delta \mathrm{T})^{0.33} \exp \left\{4.6\left[-0.54\left(\mathrm{R}_{\mathrm{\rho}}-1\right)\right]\right\}} .
$$

For characteristic parameters of the contact zone, $\mathrm{R}_{\rho}=2.6, \alpha \mathrm{D}_{\mathrm{m}}=0.052$ and $\mathrm{v}=1.88 \cdot 10^{-6} \mathrm{~m}^{2} \mathrm{~s}^{-1}, \mathrm{~d}_{\mathrm{c}}=0.011$ $\mathrm{m}$ or $11.4 \mathrm{~mm}$. The small magnitude of $d_{c}$ implies that the development of the convective layer is nearly synchronous with the development of the gradient layer at its border.

The critical Rayleigh's number $\mathrm{Ra}_{\text {cr }}$ is given by

$$
\mathrm{Ra}_{\mathrm{cr}}=\frac{\alpha \mathrm{g} \Delta \mathrm{Td}_{\mathrm{c}}{ }^{3}}{\nu \mathrm{k}_{\mathrm{t}}}=\frac{1.58 \cdot 10^{6}}{\left\{\exp 4.6\left[-0.54\left(\mathrm{R}_{\mathrm{\rho}}-1\right)\right]\right\}^{3}} .
$$

The dependence $R a_{c r}=f\left(R_{\rho}\right)$ is shown in Fig. (5).

The time, $\mathrm{t}_{0}$, of formation of the convective uniform layer with thickness $\mathrm{h}_{0}$, is determined from the balancing Turner ratio,

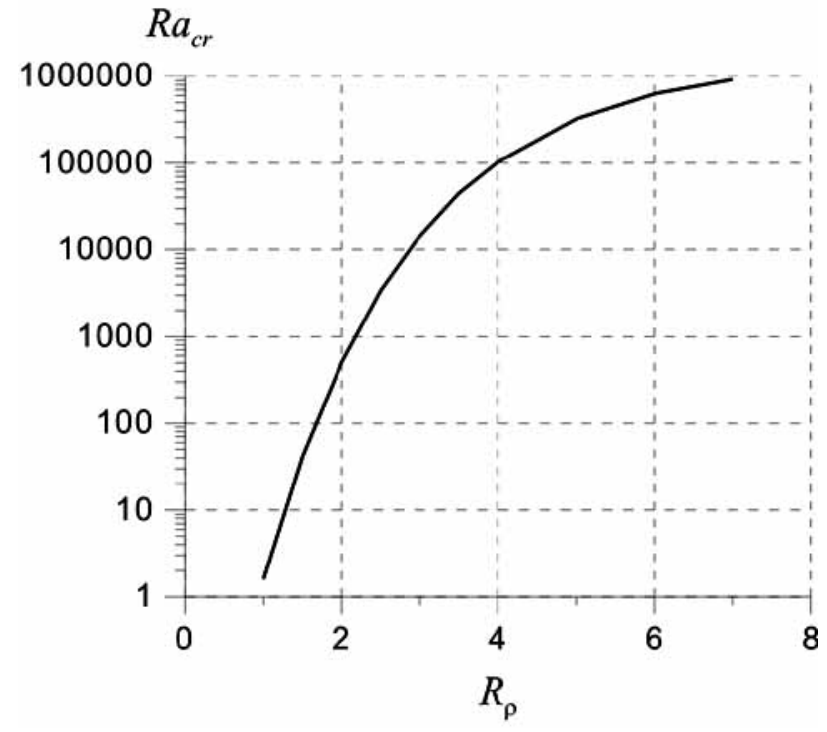

Fig. (5). Dependence of the critical Rayleigh's number $\mathrm{Ra}_{\mathrm{cr}}$ at the density ratio $R_{\rho}$.

$\mathrm{t}_{0}=\left(\frac{\mathrm{h}_{0} \mathrm{~N}}{\mathrm{C}}\right)^{2} \mathrm{q}^{-1}$,

where $\mathrm{q}_{\mathrm{b}}=\mathrm{g} \alpha \mathrm{F}_{\mathrm{T}}$ is the vertical flux of buoyancy, $\mathrm{N}^{2}=\mathrm{g} \beta \Delta \mathrm{S} / \mathrm{d}_{\rho}$ is the square of the Brunt-Väisälä frequency due to the vertical salinity gradient, and $\mathrm{C}$ is a constant whose value, according to Turner's data, lies within the range 1.06 to 1.63. Substituting $\mathrm{N}^{2}$ and $\mathrm{q}_{\mathrm{b}}$ in Eq. (15), after transformation gives the expression for the vertical velocity, $\mathrm{w}_{\mathrm{c}}$, of the development of convective layer:

$$
\begin{aligned}
& \mathrm{w}_{\mathrm{c}}=1.17 \mathrm{C}\left(\frac{\mathrm{F}_{\mathrm{T}}}{\Delta \mathrm{T}}\right)\left[\frac{\ln \left(2.58 \mathrm{R}_{\rho}^{1.5}\right)}{\mathrm{R}_{\rho}-0.15}\right]^{0.25}\left(\mathrm{R}_{\rho}\right)^{-0.5}= \\
& 1.91\left(\frac{\mathrm{F}_{\mathrm{T}}}{\Delta \mathrm{T}}\right)\left[\frac{\ln \left(2.58 \mathrm{R}_{\rho}{ }^{1.5}\right)}{\mathrm{R}_{\rho}-0.15}\right]^{0.25}\left(\mathrm{R}_{\rho}\right)^{-0.5} .
\end{aligned}
$$

Using this ratio, calculations are made for conditions that are characteristic for the zone of contact between AtW and ArW. The results are shown in Fig. (6). For the most typical conditions in the ice edge zone, the velocity of development of convective layer is $1-4 \mathrm{~m} /$ day.

\section{ANALYSIS OF THE EXPERIMENTAL DATA AND COMPARISON WITH THE CALCULATED RATIO}

As has already been described, mixed layers with a range of thicknesses that are uniform in temperature, salinity and density are found out in many CTD-profiles in the ice edge zone. Some examples of such structures are shown in Fig. (3). Concrete values of temperature and salinity shifts between AtW and ArW \& MIW are determined from the analysis of $\mathrm{T}, \mathrm{S}-$ curves. Two characteristic examples of temperature, salinity, and density are shown in Figs. (7 and 8). In the first, the development of the convective layer occurs inside the pycnocline and is symmetric in nature, i.e. with approximately equal temperature and salinity shifts at 


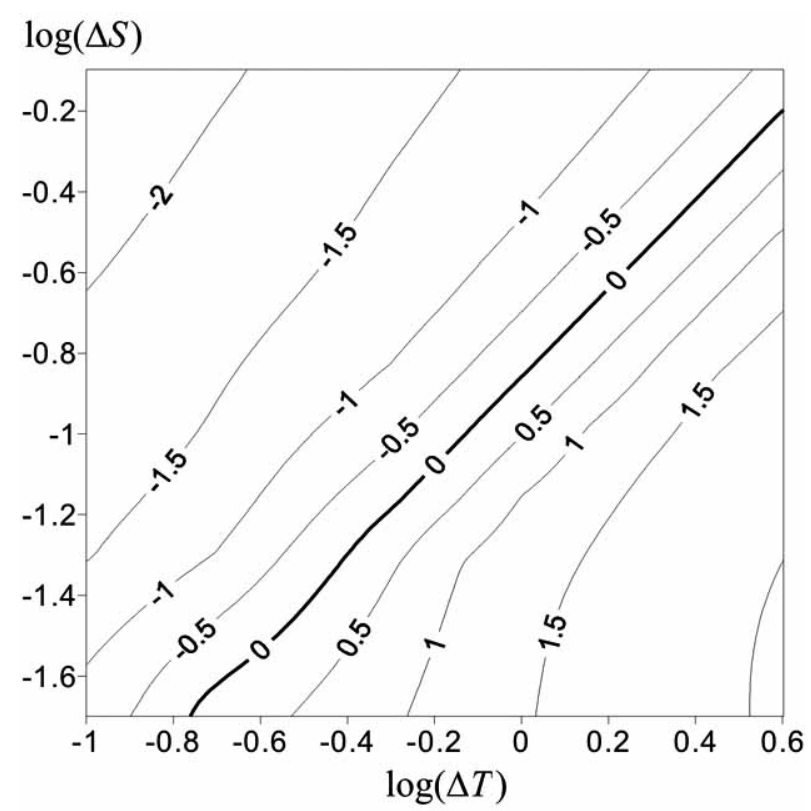

Fig. (6). The vertical convective velocity $\left(\mathrm{W}_{\mathrm{c}}, \mathrm{m} /\right.$ day) for a range of differences in temperature and salinity $\left(\Delta \mathrm{T},{ }^{\circ} \mathrm{C} ; \Delta \mathrm{S}\right.$, psu) in the contactzone between AtW and ArW. The isoline $\log \mathrm{W}_{\mathrm{c}}=0$ corresponds to velocity of $1 \mathrm{~m} /$ day.
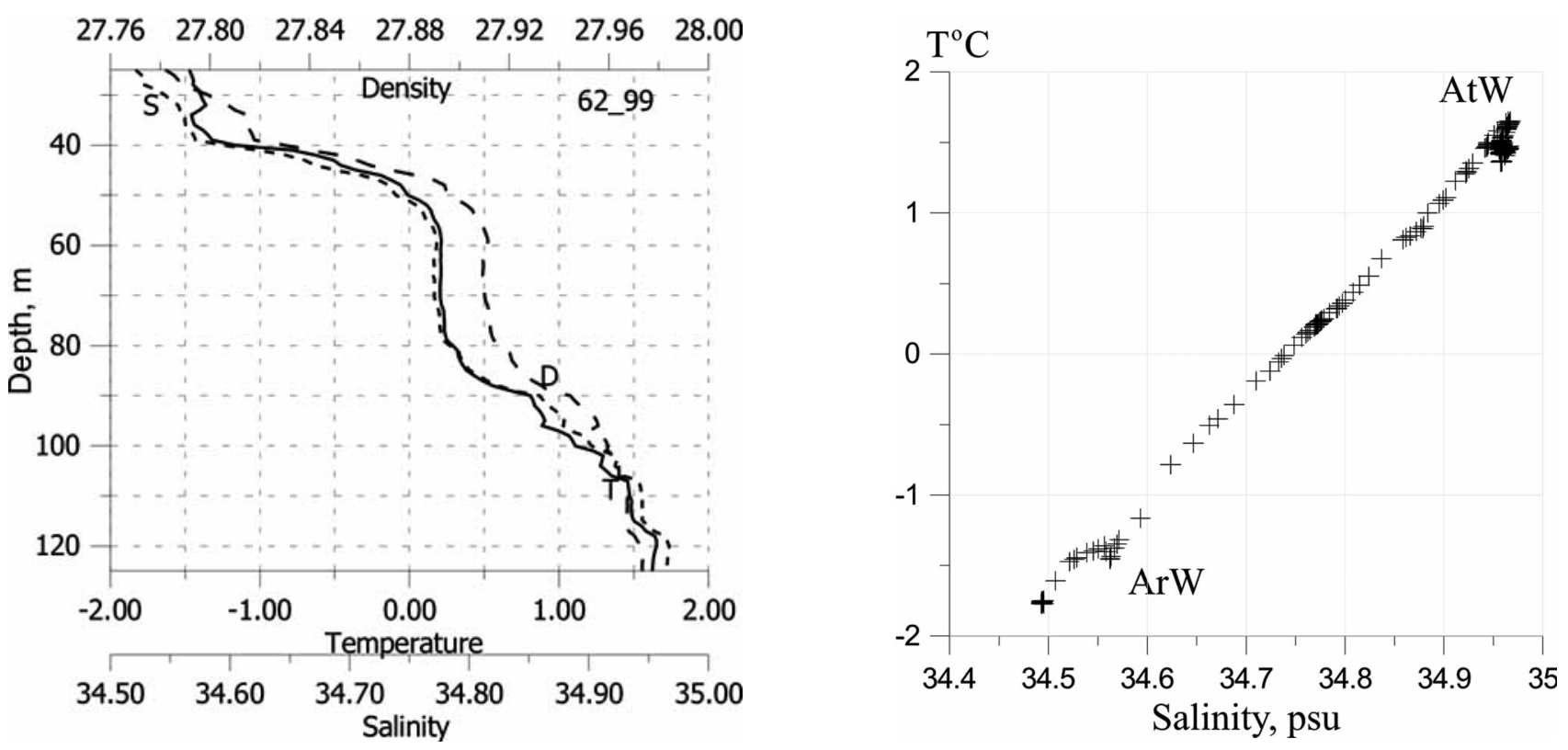

Fig. (7). Profiles of temperature, salinity, density (left panel) and the resulting T,S relation (right panel), showing the development of the convective layer inside the pycnocline.

the top and bottom of the convective layer. In about $80 \%$ of cases development of the convective layer occurs in another way. For temperature, the layer develops almost up to the surface, whereas salinity and density have sharp gradient layers in the near-surface layer, at a depth of $12-20 \mathrm{~m}$. There is almost no change in temperature whilst salinity changes by up to $0.15 \mathrm{psu}$, thus there is a strong density gradient which blocks vertical temperature flux, acting from AtW, as shown in Fig. (8).
The data for temperature and salinity changes are used to estimate the density ratio $R_{\rho}$ and the temperature flux in the zone of AtW, ArW and MIW contact using the following:

$$
\begin{aligned}
& \mathrm{R}_{\rho}=\frac{0.806 \Delta \mathrm{S}}{(0.052+0.013 \mathrm{~T}) \Delta \mathrm{T}} \\
& \mathrm{F}_{\mathrm{T}}=3.813 \cdot 10^{-6}(0.052+0.013 \mathrm{~T})^{0.333} \Delta \mathrm{T}^{1.333} \exp \left\{4.6 \exp \left[-0.54\left(\mathrm{R}_{\rho}-1\right)\right]\right\}
\end{aligned}
$$



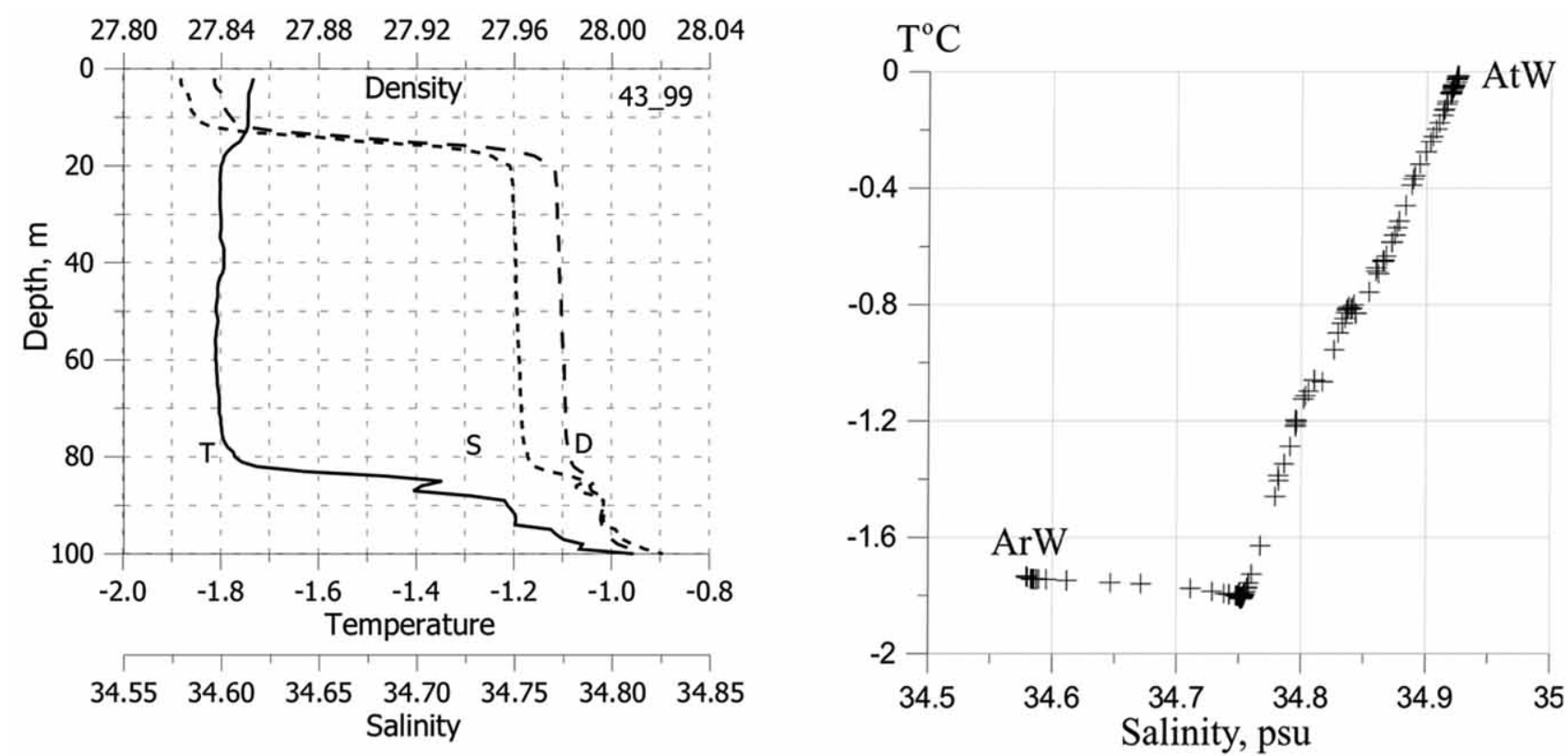

Fig. (8). Profiles of temperature (T), salinity (S), density (D) (left panel) and the corresponding T,S relation (right panel), for the case of the convection development down to a near-surface layer.

in which the dependence on average temperature, $\mathrm{T}$, of the coefficient of temperature expansion $\alpha=\mathrm{f}(\mathrm{T})$, and values of $v=1.88 \cdot 10^{-6} \mathrm{~m}^{2} \mathrm{~s}^{-1}$ and $\mathrm{k}_{\mathrm{t}}=1.34 \cdot 10^{-7} \mathrm{~m}^{2} \mathrm{~s}^{-1}$, that are characteristic for ice edge zones are used.

Data for the temperature flux and density ratio are used to estimate the thickness of the gradient layer using Eq. (11). The time of formation, $t$ of a quasi -uniform convective layer with thickness $h_{\text {cr }}$ comes into this equation. Its value is determined from the ratio $t=h_{c r} / w_{c}$, where $h_{c r}$ is the thickness of the convective layer from an observed CTDprofile. The calculated thickness of the gradient layer, $d_{\rho}$, at the border of the convective layer; the appropriate value, $\mathrm{h}_{\text {grad }}$; the changes in temperature, $\Delta \mathrm{T}$, and salinity, $\Delta \mathrm{S}$; the density ratio $R_{\rho}$; the vertical temperature flux, $F_{T}$, and the velocity of convective layer formation $\mathrm{w}_{\mathrm{c}}$ are presented in Table 1. A comparison of $d_{\rho}$ and $h_{\text {grad }}$ is shown in Fig. (9). The reliability level, $\mathrm{R}$, appropriate to a single deviation of the received data from a line of equal values, is shown in the same figure.

Using data from one of the hydrological surveys of the ice edge zone, the horizontal distribution of velocity of development of the convective layer was calculated. This distribution is superimposed onto satellite measurements of the concentration of the chlorophyll-a, which were carried out in the same period of time (Fig. 10).

\section{CONCLUSIONS}

The agreement between the calculated value of the gradient layer and its actual value supports the mechanism considered for the formation of the convective layer.

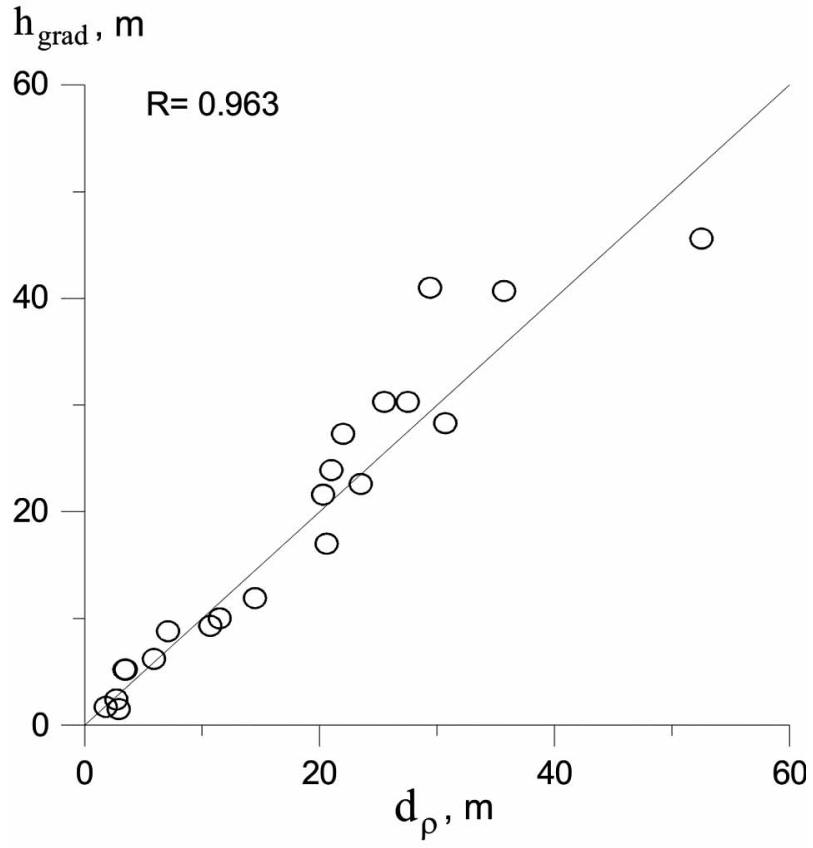

Fig. (9). Comparison of the actual gradient layer thickness, $h_{\text {grad, }}$, and the computed value, $d_{\rho}$. 
Table 1. The Main Parameters of the Contact Zone of AtW with ArW \& MIW

\begin{tabular}{|c|c|c|c|c|c|c|c|c|c|}
\hline $\begin{array}{c}\begin{array}{c}\text { No } \\
\text { Station }\end{array} \\
26 \_1999\end{array}$ & 76.3080 & 32.1300 & $\begin{array}{c}\begin{array}{c}\Delta \mathbf{T} \\
\left({ }^{\circ} \mathrm{C}\right)\end{array} \\
0.204\end{array}$ & $\begin{array}{c}\begin{array}{c}\Delta \mathrm{S} \\
(\mathbf{p s u})\end{array} \\
0.0209\end{array}$ & $\begin{array}{c}\mathbf{R}_{\rho} \\
1.40\end{array}$ & $\begin{array}{c}\begin{array}{c}\mathbf{W}_{\mathbf{c}} \\
\text { (m/day) }\end{array} \\
9.50\end{array}$ & $\begin{array}{c}\begin{array}{c}\mathrm{F}_{\mathrm{T}} \cdot \mathbf{1 0}^{\mathbf{6}} \\
\left({ }^{\circ} \mathrm{C} \mathrm{m} / \mathrm{s}\right)\end{array} \\
5.58\end{array}$ & $\begin{array}{c}\begin{array}{c}\mathbf{d}_{\rho} \\
(\mathbf{m})\end{array} \\
6.2\end{array}$ & $\begin{array}{r}\mathbf{h}_{\text {gard }} \\
(\mathbf{m})\end{array}$ \\
\hline 41_1999 & 76.8733 & 32.7750 & 1.370 & 0.1085 & 1.88 & 5.12 & 32.59 & 22.6 & 23.5 \\
\hline $42 \_1999$ & 76.8783 & 32.8350 & 1.166 & 0.0915 & $1 . .90$ & 4.98 & 25.30 & 40.7 & 35.7 \\
\hline 44_1999 & 76.8150 & 32.8200 & 0.931 & 0.0742 & 1.93 & 4.82 & 17.98 & 11.9 & 14.5 \\
\hline 45-1999 & 76.8033 & 32.8617 & 1.280 & 0.1040 & 1.92 & 4.90 & 28.91 & 23.9 & 21.0 \\
\hline 47-1999 & 76.6425 & 33.0533 & 1.070 & 0.0784 & 1.80 & 5.59 & 26.90 & 27.3 & 22.0 \\
\hline 48_1999 & 76.6333 & 33.1217 & 0.693 & 0.0550 & 1.97 & 4.64 & 6.74 & 10.0 & 11.5 \\
\hline $128 \_1999$ & 76.9417 & 27.4883 & 0.125 & 0.0680 & 14.33 & 0.07 & 0.074 & 5.2 & 3.5 \\
\hline $36 \_2000$ & 77.4267 & 33.1750 & 0.526 & 0.0470 & 2.17 & 3.76 & 6.08 & 5.2 & 3.4 \\
\hline 40_2000 & 76.9167 & 31.9833 & 2.810 & 0.2620 & 1.67 & 6.54 & 119.2 & 28.3 & 30.7 \\
\hline 41_2000 & 76.8417 & 31.8333 & 2.850 & 0.2300 & 1.39 & 9.65 & 231.0 & 41.0 & 29.4 \\
\hline $42 \_2000$ & 76.8000 & 31.7167 & 2.850 & 0.2920 & 1.70 & 6.31 & 131.0 & 45.6 & 52.5 \\
\hline 43_2000 & 76.7250 & 31.5667 & 1.725 & 0.1410 & 1.55 & 7.67 & 77.41 & 30.3 & 27.5 \\
\hline 57_2000 & 77.1433 & 27.3833 & 0.196 & 0.0353 & 2.77 & 2.26 & 0.82 & 1.5 & 2.9 \\
\hline $59 \_2000$ & 77.0467 & 28.0350 & 0.203 & 0.0401 & 5.28 & 0.58 & 0.22 & 1.7 & 1.8 \\
\hline
\end{tabular}

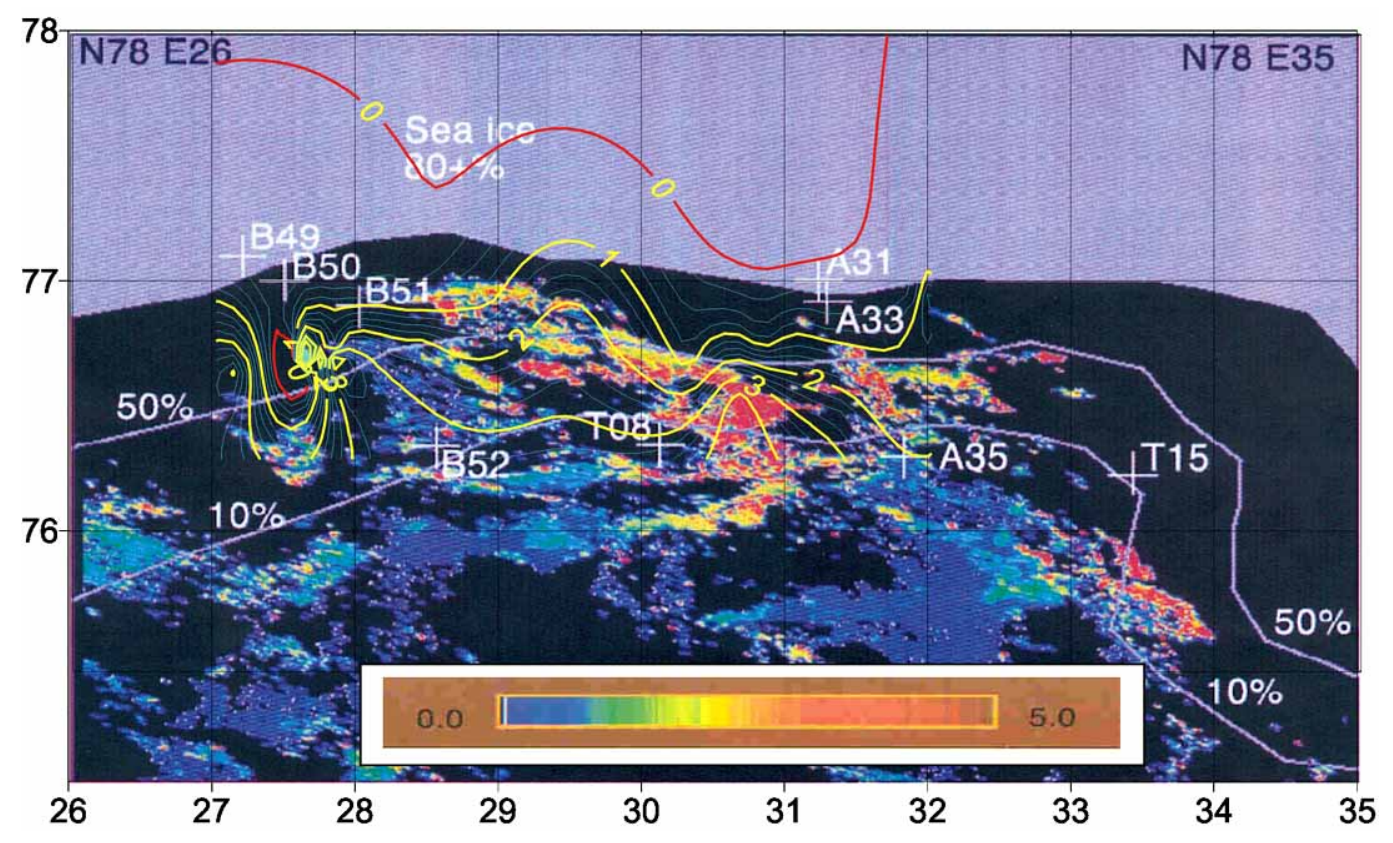

Fig. (10). Distribution of velocity of convective structures formation (the yellow isolines conducted through $1 \mathrm{~m} / \mathrm{day}$ ) and distribution of the chlorophyll concentration on the data of satellite measurements. 
The expression for velocity of development of the convective instability in the stratified layer can be used to calculate the convective structures in zones of contact of cold, low-salinity waters with warm, higher-salinity waters. It is possible that convective instability is the considered type concern to the basic mechanisms of formation of vertical structure of waters and its mixing.

Balancing Turner's ratio, as used in the analysis, is adequate to describe the observed processes of double-diffusive convection in the ice edge zones.

The vertical velocity of the convective instability in the investigated area changes over a wide range, from $0.1 \mathrm{~m} /$ day up to $10 \mathrm{~m} /$ day. Its average value is equal to the $1 \mathrm{~m} /$ days.

Satellite measurements of the concentration of chlorophyll-a in ice edge areas indicate a relationship between areas of maximum velocity of convective instability development and the maximum concentration of chlorophyll-a. There is also an absence of chlorophyll-a in the small area of zero convection velocity. This single comparison cannot be the basis for concluding that the velocity of convection development in the stratified sea layer has a simple connection with the characteristics of initial production. Nevertheless, it can serve as a starting point for more detailed research.

\section{ACKNOWLEDGMENTS}

This work is carried out within the framework of the project "Norwegian Component of the Ecosystem Studies of Subarctic and Arctic Regions (NESSAR)". The Research Council of Norway (RCN), the International Polar Year initiative, funds the project.

\section{REFERENCES}

[1] Loyning TB. Hydrography in the north-western Barens Sea. Pol Res 2001; 20(1): 1-11.

[2] Tareev BA. Two theories of the convective circulations in deepwater troughs of the Ocean. Izv USSR Acad Sci Ser Geophys 1960; 7: 1022-9. (In Russian).

[3] Turner JS. Behaviour of a stable salinity gradient heated from below. J Fluid Mech 1968; 33(10): 183-200.

[4] Veronis G. Effect of stabilizing gradient of solute on thermal convection. J Fluid Mech 1968; 34: 315-36.

[5] Huppert HE. Stability of a series of double-diffusive layers. DeepSea Res 1971; 18(10): 1005-21.

[6] Linden PE, Shirtcliffe TGL. The diffusive interface in doublediffusion convection. J Fluid Mech 1978; 87: 417-42.

[7] Turner JS. Small-Scale Mixing Processes. In: Warren BA, Wunsch C, Eds. Evolution of physical oceanography. The MIT Press 1981; 236-62.

[8] Huppert HE, Turner JS. Double-diffusive convection. J Fluid Mech 1981; 106: 299-329.

[9] Busse FH. Transition to turbulence in the Rayleigh-Benardconvection. In: Swinney HI, Gollub JP, Eds. Hydrodynamic Instabilities and the Transition to Turbulence. Mir, Moscow, USSR 1984; 124-168.

[10] Fedorov KN. Thickness of layers and coefficients of exchange at the layer's convection in the Ocean. Izv USSR Acad Sci 1985; 287(5): 574-93.

[11] Fernando HJS. The formation of layered structure when a stable salinity gradient is heated from below. J Fluid Mech 1987; 182: 525-41.

[12] Eremeev VN, Kushnir VM. Thermodynamic parameters of the deep-water near-bottom layer in the Black Sea. Acad Sci Ukraine 1994; 6: 104-8.
[13] Kushnir VM. Thermal fluxes and stability of the upper boundary of the abyssal Black Sea near-bottom layer. Mar Hydr J 1996; 1: 3545 .

[14] Eremeev VN, Kushnir VM. The layered structure of currents and the vertical exchange in the Black Sea. Oceanology 1996; 36(1): 13-19.

[15] Fernando HJS, Brandt A. Recent advances in double-diffusive convection. Appl Mech Rev 1994; 47: c1-c7.

[16] Hansen U, Yuen DA. Formation of layered structures in doublediffusive convection as applied to the geosciences. In: Brandt A, Fernando HJS, Eds. Double-diffusive convection, AGU 1996; 13549.

[17] Hyun MT, Bergman TL. Direct simulation of double-diffusive layered convection. J Heat Transfer 1995; 117: 334-9.

[18] Kerpel J, Tanny J, Tsinober A. On a stable solute gradient heated from below with prescribed temperature. J Fluid Mech 1991; 223: 83-91.

[19] Kranenbourg EJ, Dijkstra HA. Double diffusive layer formation near a cooled liquid-solid boundary. Int J Heat Mass Transfer 1998; 41: $1873-84$

[20] May BD, Kelley DE. Dynamics of thermohaline intrusions in the Arctic Ocean. J Geophys Res 2001; 106: 16,783-94.

[21] Schmitt RW. Double diffusion in oceanography. Ann Rev Fluid Mechanics 1994; 26: 255-85.

[22] Walsh D, Ruddick B. Double-diffusive interleaving in the presence of turbulence: The effect of a nonconstant flux ratio. J Phys Oceanogr 2000; 30: 2231-45.

[23] Alford M, Pinkel R. Patterns of turbulent and double-diffusive phenomena: observations from a rapid-profiling microconductivity Probe. J Phys Oceanogr 2000; 30(5): 833-54.

[24] Edwards NR, Richards KJ. Linear double-diffusive-inertial instability at the equator. J Fluid Mech 1999; 395: 295-319.

[25] Gregg MC, Ozsoy E. Mixing on the Black Sea shelf north of the Bosphorus. Geophys Res Lett 1999; 26: 1869-72.

[26] Dewey RK, Muench RD, Gunn JT. Mixing and vertical heat flux estimates in the Arctic Eurasian Basin. J Mar Syst 1999; 21: 199205.

[27] Fedorov KN. On the step structure of temperature inversions in the ocean. Izv USSR Acad Sci Phys Atmos Ocean 1970; 6(11): 117888.

[28] Newman FC. Temperature steps in Lake Kivu: a bottom heated saline lake. J Phys Oceanogr 1976; 6(2): 157-63.

[29] Murray JW, Top Z, Ozsoy E. Hydrographic properties and ventilation of the Black-Sea. Deep-Sea Res Part A- Oceanogr Res Pap 1991; 38: S663-S89.

[30] Benard C, Benard R, Bennacer R, Gobin D. Melting driven thermohaline convection. Phys Fluids 1996; 8(1): 112-30.

[31] Kushnir VM, Hansen E, Pavlov VK, Morozov AN. Thermochaline convection in the edge ice zone in the Barents Sea to the east of Spitsbergen. Mar Hydr J 2003; 6: 65-77. (In Russian). English translation in: Phys Oceanogr Nov 2003; 13(6): 361-74. doi:10. 1023/B:POCE.0000013233.69589.d1.

[32] Bianchi AA, Piola AR, Collino GJ. Evidence of double diffusion in the Brazil-Malvinas Confluence. Deep-Sea Res 2002; 49(1): 41-52.

[33] Kuzmina NP, Zhurbas V. Effects of double diffusion and turbulence on interleaving at baroclinic oceanic fronts. J Phys Oceanogr 2000; 30: 3025-38.

[34] May BD, Kelley DE. Growth and steady state stages of thermohaline intrusions in the Arctic Ocean. J Geophys Res 2001; 106: 78394.

[35] Ozsoy E, Iorio DD, Gregg M, Backhaus J. Mixing in the Bosphorus Strait and the Black Sea Continental Shelf: observations and a model of the dense water outflow. J Mar Syst 2001; 31: 99-135.

[36] Rudels B, Bjork G, Muench RD, Schauer U. Double-diffusive layering in the Eurasian Basin of the Arctic Ocean. J Mar Syst 1999; 21: 3-27.

[37] Neshyba S, Neal VT, Denner W. Temperature and conductivity measurements under Ice Island T-3. J Geophys Res 1971; 76 : 8170-20.

[38] Marmorino GO, Caldwell DR. Heat and salt transport through a diffusive thermohaline interface. Deep-Sea Res 1976; 23(1): 59-67. 
[39] Engelsen O, Hegseth EN, Hop H, Hansen E, Falk-Petersen S. Spatial variability of chlorophyll-a in the Marginal Ice Zone of the
Barents Sea, with relation to sea ice and oceanographic conditions. J Mar Syst 2002; 35: 79-97.

(C) Kushnir et al.; Licensee Bentham Open.

This is an open access article licensed under the terms of the Creative Commons Attribution Non-Commercial License (http://creativecommons.org/licenses/ by-nc/3.0/) which permits unrestricted, non-commercial use, distribution and reproduction in any medium, provided the work is properly cited. 